\title{
Situational Analysis of Access to Improved Sanitation in the Capital of Ethiopia and the Urgency of Adopting an Integrated Fecal Sludge Management (FSM) System
}

\author{
Abebe Beyene ${ }^{1}$, Taffere Addis ${ }^{1}$, Tamene Hailu ${ }^{2}$, Esubalew Tesfahun ${ }^{3}$, Mikiyas Wolde ${ }^{2}$, \\ Kebede Faris ${ }^{4}$ \\ ${ }^{1}$ Department of Environmental Health Science and Technology, Jimma University, Jimma, Ethiopia \\ ${ }^{2}$ Research and Development Directorate, Ministry of Water, Irrigation and Energy (MoWIE), Addis Ababa, Ethiopia \\ ${ }^{3}$ School of Public Health, Addis Ababa University, Addis Ababa, Ethiopia \\ ${ }^{4}$ Water and Sanitation Programme (WSP), the World Bank, Ethiopia Country Office, Addis Ababa, Ethiopia \\ Email address: \\ abebe.beyene@ju.edu.et (A. Beyene)
}

\section{To cite this article:}

Abebe Beyene, Taffere Addis, Tamene Hailu, Esubalew Tesfahun, Mikiyas Wolde, Kebede Faris. Situational Analysis of Access to Improved Sanitation in the Capital of Ethiopia and the Urgency of Adopting an Integrated Fecal Sludge Management (FSM) System. Science Journal of Public Health. Vol. 3, No. 5, 2015, pp. 726-732. doi: 10.11648/j.sjph.20150305.29

\begin{abstract}
In the faces of alarming urbanization and the high demand for basic sanitation, there are debts that urban sanitation in Sub-Saharan Africa has been steadily improving in one hand and worsening on the other hand in the recent decades. The objective of this research was to investigate the status of urban sanitation coverage in relation to Millennium Development Goal (MDG) 2015 target and the major gaps of fecal sludge management (FSM) system. For this purpose, we conducted the sanitation coverage survey in the urban slums of Addis Ababa and we compared it with the nationwide sanitation inventory conducted by Ethiopian Minister of Water, Irrigation and Energy (EMWIE) in 2014. The results revealed that only $11.4 \%$ of urban slum residents have access to improved sanitation. This sanitation coverage is by far lower than the improved sanitation coverage of the capital city $(41.2 \%)$ and the national urban sanitation coverage (27\%). Open defecation being a common practice in urban areas of Ethiopia accounts $8.2 \%, 5.8 \%$ and $8.0 \%$ for urban slums of the capital and all urban areas of the country respectively. Despite the increasing trend in urban sanitation coverage in Ethiopia, it is far from the MDG target and the majority of urban residents are living under severe health and environmental risks. The urban poor are the ones mainly excluded from the basic sanitation services. Most sanitation facilities (about 91\%) in Addis Ababa are onsite sanitation that requires pit emptying nevertheless $85.4 \%$ of the residents dissatisfied with the pit emptying services. As results of the severe constraints of pit emptying and FSM services, most toilet facilities (about 50\%) were full. The FSM system is totally ineffective to tackle environmental pollution and public health risks. This calls an urgent action towards the development of integrated FSM system that ensures environmental safety and targets valorization of human waste.
\end{abstract}

Keywords: Fecal Sludge Management, Sanitation Status, Urban Slum, Addis Ababa, Ethiopia

\section{Introduction}

Cities in developing countries are facing unprecedented demographic, environmental, economic, social and spatial challenges. One of the key 21 st century global challenges in public health is improving the urban sanitation related problems [1, 2]. Since 2007, more people live in urban centers than in rural areas and this trend is expected to continue. Within the next 30 years, developing countries are predicted to account for $80 \%$ of the world's urban population.
Around one third of urban dwellers are living in urban slums of which more than $90 \%$ urban slums are located in developing countries [3]. Sub-Saharan Africa is urbanizing faster than any other continent having currently $37 \%$ urbanized population [4]. In 2012, $61.7 \%$ of the SubSaharan Africa urban population live in slums where sanitation situation is highly deteriorated [5]. From an urban perspective, in Sub-Saharan Africa challenges related to water and sanitation will be higher in the future due to an ever-growing city population that share already insufficient and poorly managed resources. 
An improved sanitation is defined as a sanitation system that hygienically separates human excreta from human contact [6] as depicted in the conceptual diagram (Figure 1). Sanitation is the single most cost-effective public health intervention to reduce child mortality [7, 8]. However, lack of improved sanitation is the most important feature of slums in the African urban context. The MDG sanitation target was to reduce the proportion of the world population without access to improved sanitation from $51 \%$ in 1990 to $25 \%$ in 2015. Despite progresses, meeting the MDG sanitation target is lagging behind and becomes a challenging task in developing countries mainly in Sub-Saharan countries [4]. According to the report, Ethiopia is in the list of countries that are not on track to meet MDG sanitation target, nevertheless, administrative reports claimed that the country is on the right track to meet the MDG.

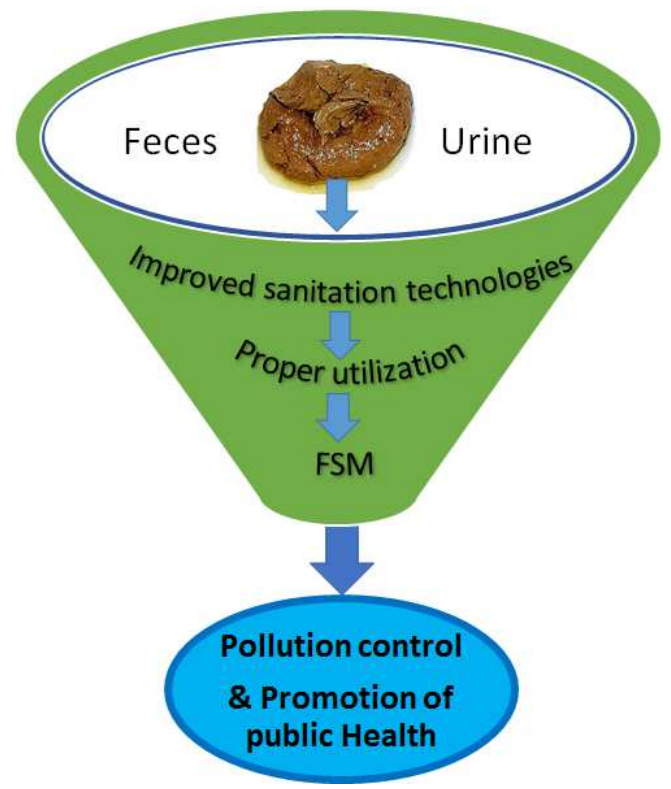

Figure 1. Conceptual diagram of access to improved sanitation technology supplemented with proper utilization and fecal sludge management (FSM) to protect the environment and promote public health.

In Ethiopia, the urban population is growing at an average rate of $5.84 \%$ for last fifty years (1961-2013), which has resulted with about 755.6 people adding to the urban residents daily [9]. The urban population is now expected to double in the next two decades to reach $30.1 \%$ by the year 2020. Addis Ababa is one of the largest cities in Africa with more than 3 million residents. Since $80 \%$ of residents of Addis Ababa live in urban slums, its people have been facing serious sanitation problems [2, 10]. The rapidly increasing demand for sanitation and deteriorating rate of access to improved sanitation in Addis Ababa calls for detail research investigation. Identifying the current levels of access and investigating trends in which direction the city is heading, and identifying the driving factors will become more important as Addis Ababa grow larger and struggle to provide these basic services to their residents. Therefore, one of the objectives of this research is to assess the status and trends of urban sanitation in Addis Ababa.
Most attention for monitoring of the progress of access to sanitation worldwide has been mainly focused on householdlevel inventory of type and number of toilet facilities ignoring proper utilization and user behavior [11]. As reported by Bartram and Cairncross et al. [12], different levels of access along the sanitation ladder provide widely varying health benefits. For instance, the change from open defecation to the use of an improvised latrine is a step forward, but is unlikely to offer health benefits unless the latrine provides an adequate barrier between the users and their excreta. Hence, access to improved sanitation should consider the complete fecal sludge management (FSM) chain from containment to adequate treatment including waste valorization for sustainable sanitation system. In this regard, detail study is required to see the complete picture of sanitation service in relation to its aptness for pollution control and minimizing public health risks. The second objective of this research is therefore to investigate the chain of FSM system from confinement to disposal in relation to access to improved sanitation.

\section{Study Area and Method}

\subsection{Study Area Description}

The study was focused on Addis Ababa, the capital of Ethiopia and Africa. It is located at $9^{\circ} 1^{\prime} 48^{\prime \prime} \mathrm{N}$ and $38^{\circ} 44^{\prime}$ 24" E with an average elevation of 2355 m.a.s.1. The estimated area of the city is $527 \mathrm{~km}^{2}$ with a population density of 5165 persons $/ \mathrm{km}^{2}$. It is considered as one of the largest cities in Africa with more than 3 million residents. The population is projected to grow by $3.8 \%$ per year.

\subsection{Method}

We compiled the improved sanitation coverage (ISC) of the administrative government report (AGR) from Ethiopian Ministry of Health $(\mathrm{MoH})$ that are available under the topics of "health and health related indicators" as well as the Ethiopian Central Statistical Authority (CSA) survey data. Finally, the trends of access to ISC were plotted to see the real variability through time both for Addis Ababa and urban Ethiopia. The sanitation ladder, which was established by JMP (WHO and UNICEF, 2008), is a useful tool for monitoring progress towards the MDGs. Nationwide inventory of sanitation facilities in accordance to the sanitation ladder was conducted by Ethiopian Ministry of Water, Irrigation and Energy in the year 2014. The inventory data were compiled and analyzed to verify the current status of improved urban sanitation coverage in relation to the MDG target. In addition, we also conducted inventory of sanitation facilities in accordance to the sanitation ladder in randomly selected urban slums of Addis Ababa in the year 2013 and 2014 to investigate the status of ISC in the urban poor segment of the population. We calculated the sample size based on Daniel and Cross [13] considering 10\% none response rate, $5 \%$ margin of error and $50 \%$ proportion that will give the maximum sample size. Based on these 
assumptions, the calculated sample size is 403 households. To select the households, 5 sub-cities were randomly selected from a total 10 sub-cities in Addis Ababa. Then, we selected randomly 2 districts from each sub-city. Finally, we selected purposively a total of 40 households of urban slum area from each selected districts. In total 400 households were involved for the survey. We used both face-to-face interview and observation using semi-structured questionnaire and checklist respectively. Environmental and public health professionals were the data collectors for the sanitation field survey. Finally, we entered the data into SPSS statistical software version 16.0, and performed data cleaning and analysis.

\section{Results}

\subsection{Current Status of Sanitation}

Table 1. Current sanitation coverage at different levels of the sanitation ladder in the capital city and urban national scale.

\begin{tabular}{|c|c|c|c|c|c|}
\hline \multirow{2}{*}{ Sanitation status } & \multirow{2}{*}{ Sanitation ladder } & \multicolumn{2}{|l|}{ Addis Ababa } & \multicolumn{2}{|l|}{ Ethiopia } \\
\hline & & Urban slum (\%) * & Total (\%) ** & Urban $(\%) * * *$ & National $(\%) * * *$ \\
\hline \multirow{4}{*}{ Improved sanitation } & Pour/flush toilet & 1.0 & 20.2 & 5.3 & 0.8 \\
\hline & IPL private & 5.2 & 10.4 & 0.6 & 0.2 \\
\hline & Pit latrine private & 5.2 & 10.6 & 11.6 & 3.5 \\
\hline & Total & 11.4 & 41.2 & 17.5 & 4.5 \\
\hline \multirow{4}{*}{ Unimproved sanitation } & Shared latrine & 58.1 & 53.0 & 28.0 & 4.5 \\
\hline & USTs (e.g., open pit, bucket, etc.) & 22.3 & - & 45.8 & 56.9 \\
\hline & Open defecation & 8.2 & 5.8 & 8.7 & 34.1 \\
\hline & Total & 88.6 & 58.8 & 82.5 & 95.5 \\
\hline
\end{tabular}

Note: IPL = Improved Pit latrine; USTs = Unsanitary toilets; * = our survey result; **= Ethiopian-MoWIE, 2014; *** = CSA, 2014

\subsection{Trend of Sanitation Coverage}

The trend of access to improved sanition coverage (ISC) for urban residents of Ethiopia revealed declining over time (Fig. 2). The current access to ISC for urban residents is $17.5 \%$ which is by far less than the MDG target (75\%) of 2015. Unfortunately, the highest (44\%) and the lowest (17.5) urban-national access to ISC was reported in 2004 and 2014 respctively. Although a relatively higher access to ISC was reported in Addis Ababa than urban-national, the trend showed a sharp decrease from 2010 to 2014 (Fig. 2). The trend also revealed that urban ISC was above the MDG target from 2002 to 2010 while the recent sanition reports (2012 and 2014) were far from MDG target.

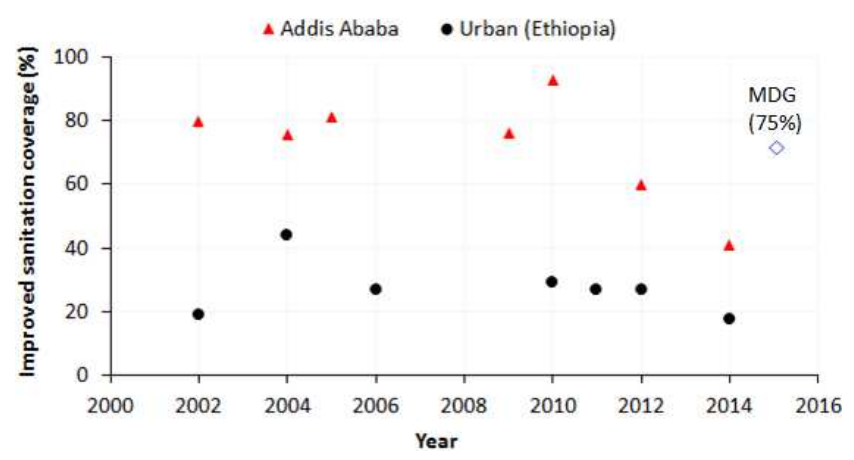

Figure 2. Trends of access to improved sanitation in Addis Ababa and urban residents of Ethiopia in relation to $M D G$. Data source: $[14,15,16]$.
We summarized the most recent sanitation coverage status along the sanitation ladder in Table 1. The current state of improved sanitation coverage only accounts $11.4 \%$ for urban slums and $41.2 \%$ for the whole urban residents of Addis Ababa. Majority of urban slums (88.6\%) used unimproved sanitation facilities including open field defecation. The Ethiopian-CSA of 2014 survey also estimated $82.5 \%$ of urban and $95.5 \%$ of national population have no access to improved sanitation. Moreover, $8.7 \%$ of urban and $34.1 \%$ of national population used open field (Table 1). The majority of sanitation facilities were dry toilets in both urban and urban slums of Addis Ababa and Ethiopia in general. For instance, dry toilet facilities accounted to $90.8 \%$ and $74 \%$ in urban slums and total urban of Addis Ababa respectively (Table 1).

\subsection{User Behavior and Pit Emptying Practice in Urban Slums}

Compositions of anal cleansing materials are the major factors influencing the decomposition processes occurring in the pit and the pit-filling rate. As shown in Table 2, the commonly used anal cleansing materials (39\%) are a combination of hard paper, tissue paper and water followed by hard paper and water (35.5\%). Among the anal cleaning materials, hard paper is the most commonly used both as a single and combined use (91.4\%). None of the households added chemicals to their toilets.

Table 2. Percentage of user behavior with regard to type of anal cleaning materials.

\begin{tabular}{lll}
\hline Type of anal cleansing material & Frequency & Percent (\%) \\
\hline Hard paper & 47 & 11.7 \\
Tissue paper & 2 & 0.5 \\
Water & 18 & 4.5 \\
Hard and tissue paper & 21 & 5.2 \\
Hard paper and water & 143 & 35.5 \\
Tissue paper and water & 15 & 3.7 \\
Hard and tissue paper, and water & 157 & 39.0 \\
\hline
\end{tabular}

Among the households which have toilet facilities, $327(88.38 \%)$ in urban slums of Addis Ababa used municipal emptying services whereas only $29(7.84 \%)$ connected their toilet facilities to the nearby rivers (Table 3 ). There is no manual pit emptying practices in the study area. 
Among the households that uses either municipal or private pit emptying services, only 59(14.6\%) were satisfied with the services. The reasons for the dissatisfaction were its in availability (waiting at least 3 months) when needed and high cost for municipal and private pit emptying services respectively. The average price for municipal pit emptying per toilet is about US\$ 9.3 and US\$ 36.0 for private pit emptying. The average pit emptying frequency was 2 times per year. As the result of the severe constraints of pit emptying services, most toilet facilities (about 50\%) were full (Figure 3).

Table 3. Type of pit emptying practices with their frequency and percentage in urban slums.

\begin{tabular}{lll}
\hline Pit emptying practice & Frequency & Percent (\%) \\
\hline Municipal emptying & 327 & 88.38 \\
Private pit emptying & 6 & 1.62 \\
Connected to sewer system & 4 & 1.08 \\
Construct new & 4 & 1.08 \\
Connected to river & 29 & 7.84 \\
\hline
\end{tabular}
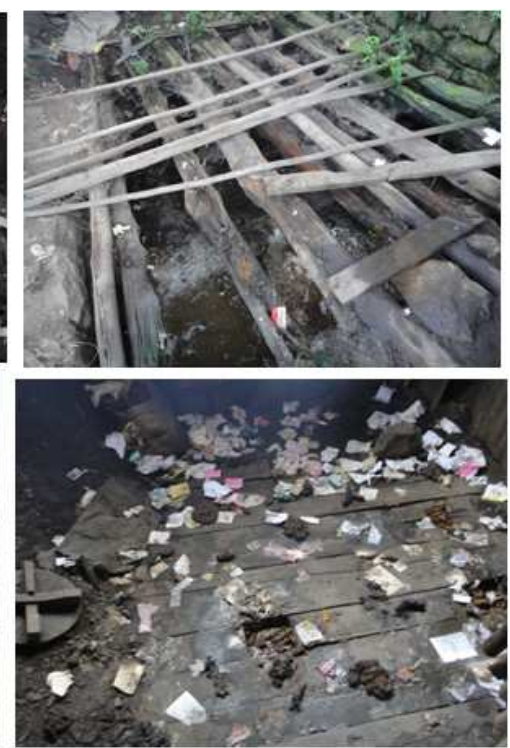

Figure 3. Photo showing full pit latrines and the residents were forced even to use the slab for defecation.

\subsection{Fecal Sludge Management}

The chain of fecal sludge Management (FSM) system of Addis Ababa is summarized in Figure 4. In the chain of FSM system, the containment was mainly dry toilets (i.e., $74 \%$ in Addis Ababa and $90.8 \%$ urban slums of Addis Ababa). In the dry toilets containment system, there was no complete treatment and safe disposal of FS. The FS from dry toilets was either partially treated with sludge drying beds to be disposed in agricultural land or directly connected to the rivers. The sludge drying bed also has no liner system that can result surface and ground water contamination. The stabilization pond treatment for flush toilets with sewer connection system was also partial and end up to rivers. Moreover, we observed few toilet facilities that were directly connected to the rivers. Resource recovery oriented FSM system was completely absent.

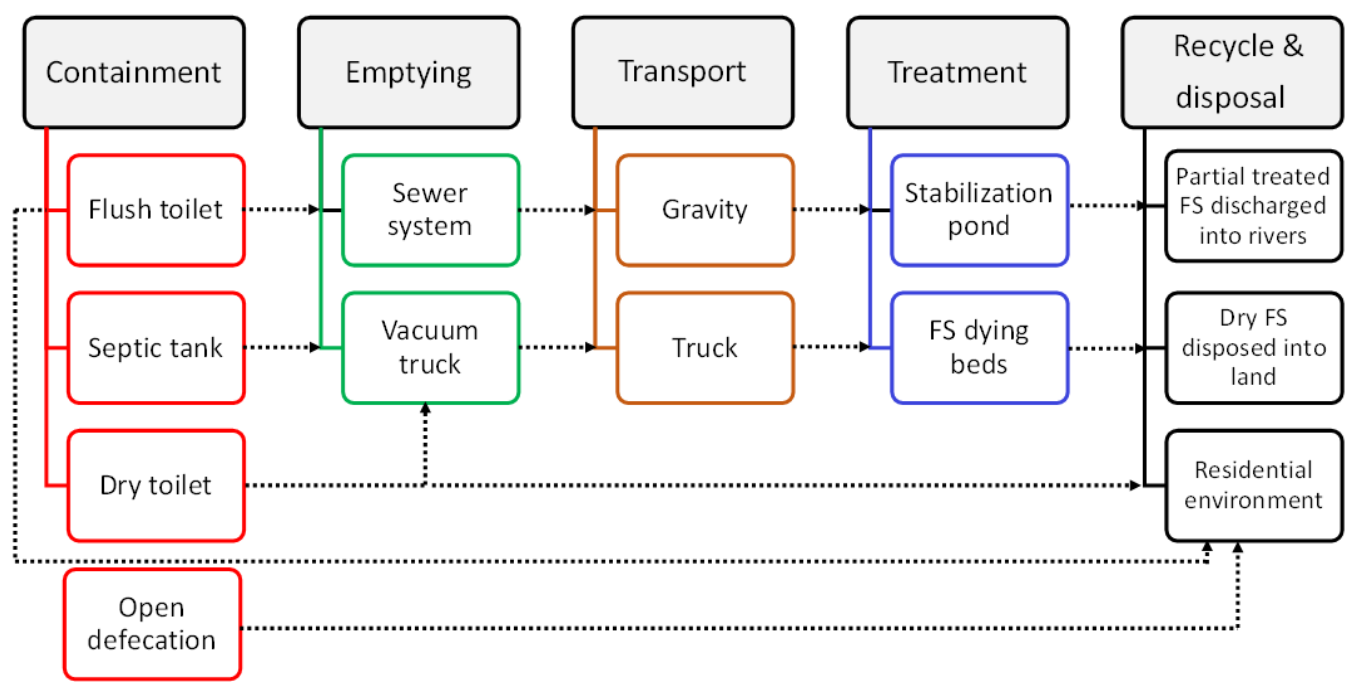

Figure 4. The chain of fecal management (FSM) system and current practices of FSM in Addis Ababa. 


\section{Discussion}

\subsection{Current Status of Sanitation}

Although MDG of access to safe water was achieved in urban Africa, access to basic sanitation facilities is far from the target and considered to be extremely difficult in SubSaharan Africa [4]. Our finding showed that the current access to improved sanitation coverage in urban residents of Ethiopia including the capital city is enormously far from the MDG target. For instance, $82.5 \%$ of urban and $95.5 \%$ of national population have no access to improved sanitation. The survey also showed that access to ISC only accounts $11.4 \%$ for urban slums and $41.2 \%$ for the whole urban residents of Addis Ababa. Majority of urban slums (88.6\%) used unimproved sanitation facilities including open field defecation, which implies that urban poor are excluded from the sanitation services. A number of researchers have documented that inadequate access to improved sanitation in Sub-Saharan Africa leads to use unsanitary toilet facilities and open field for defecation that creates significant environmental pollution [2, 17] and health hazards [18, 28, 29]. The reason behind this low access to improved sanitation is due to lack of contextualized strategies, policy and action [21] in addition to weak sectorial coordination and low national budget allocation [22].

\subsection{Trends of Sanitation Coverage}

In the faces of alarming urbanization and the high demand for basic sanitation, there are debts that urban sanitation in Sub-Saharan Africa has been steadily improving in one hand and worsening on the other hand in the recent decades. However, the trend of access to ISC for urban residents of Ethiopia revealed declining over time (44\% in 2004 to $17.5 \%$ in 2014) indicating mis-match between rural urtban migration of people and corresponding service level growth. Although a relatively higher access to ISC was reported in Addis Ababa than urban-national, the trend showed a sharp decrease from 2010 to 2014. According to the trend analysis from 2000 to 2012 condcuted by Hopewell and Graham [23] in 31 major Sub-Saharan Africa cities, Addis Ababa is listed as one of the cities found to have no significant change in terms of improved sanitation and upturn in the prevalence of open defecation. When compared with these cities, the access to improved sanitation in Addis Ababa lower than most of the cities (78.3\%) of Sub-Saharan Africa. Population growth coupled with rapid urbanization that outpace the government commitment and actions are the major potential reasons that lead to a decline access to improved sanitation.

\subsection{User Behavior and Pit Emptying Practice in Urban Slums}

The importance of sanitation to safeguard human health is well known and undisputed. Nevertheless, assess to improved sanitation coverage is only estimated based on simple counting on a hierarchy of predefined sanitation technologies [11] ignoring the functions of sanitation systems in relation to user behavior, pit emptying and FS treatment. Among the anal cleaning materials, hard paper is the most commonly used both as a single and combined use (91.4\%) that can increase the pit filling rate and create obstacle of vacuum pit emptying. None of the households added chemicals to their toilets, which facilitate microbial degradation of fecal sludge. Pit emptying of dry toilets and fecal sludge treatment are the challenges of urban sanitation $[24,25]$. Similarly, pit emptying and FS treatment were found to be the major constraints in urban slums of Addis Ababa. Among the households that uses either municipal or private pit emptying services, $85.4 \%$ were unsatisfied with the services provided due to the high price and limited number vacuum tracks that are not accessible when needed. There was also no local pit emptying technologies. As the result of these severe constraints, most toilet facilities (about $50 \%$ ) were full which forced users to defecate on the slabs and outside the toilet facilities. Our findings pointed out the urgency of developing simple and low cost pit emptying technologies.

\subsection{Fecal Sludge Management (FSM) System}

Access to improved sanitation should consider the complete FSM chain from containment to adequate treatment including valorization for sustainable sanitation system. As indicated by Bartram and Cairncross [12], access to different levels of sanitation ladder provide widely varying health benefits. For instance, the change from open defecation to the use of unimproved latrine is a step forward. Nevertheless, it is unlikely to offer health benefits unless the latrine provides an adequate barrier between the users and their excreta. Our finding showed that as containment of FS was mainly dominated by dry toilets with subsequent incomplete treatment and unsafe disposal confirming that simple counting of access to sanitation facilities will not guarantee in avoiding risk of environment contamination and public health. For example, the sludge drying beds in Addis Ababa has no liner system that can result in surface and ground water contamination besides the risks from subsequent direct agricultural application of untreated biosolids. Although flush toilets are considered improved sanitation facilities, their fecal sludge was either connected to the river or only partially treated by stabilization ponds. It is evident that untreated urban waste is grossly polluting the nearby lakes and rivers in Sub-Saharan Africa [26, 27, 28]. The outflow of highly polluted rivers in Addis Ababa are mere threats to downstream water sources.

We observed that resource recovery oriented [29] and safe FSM system is totally absent in Addis Ababa. Hence, future monitoring and evaluation of progress for access to improved sanitation coverage should consider the effectiveness of the complete FSM chain in addition to inventory of sanitation technologies. 


\section{Conclusion}

The current access to improved sanitation coverage in urban residents of Ethiopia including the capital city is far from the MDG target. The coverage is also declining because of uncontrolled population growth and high urbanization. Pit emptying services were inadequate indicating the need for developing affordable pit emptying technologies. Safe and resource recovery oriented FSM system is totally absent in Addis Ababa that nullify even the current low access to improved sanitation coverage. Therefore, future progress updates for access to improved sanitation coverage should consider the effectiveness of the complete FSM chain in addition to inventory of sanitation technologies.

\section{Ethics}

The Addis Ababa sanitation inventory was not subjected to ethical review since it is an operational study without involving human subjects. Nevertheless, the protocols for the household survey were reviewed by the Ethical Review Board of the College of Health Sciences, Jimma University, Ethiopia and we received an ethical approval before conducting the survey.

\section{Acknowledgments}

This work is supported by Jimma University (Ethiopia), Ethiopian Ministry of Water, Irrigation and Energy (MoWIE), and Sanitation Research Fund for Africa (SRFA) from Bill and Mlinda Gate Foundation (BMGF) and Water Research Commission of South Africa with a grant agreement number K5/2293//11.

\section{References}

[1] Sclar, E.D., Garau, P. and Carolini, G. (2005). The $21^{\text {st }}$ century health challenge of slums and cities. Lancet, 365: 901-903.

[2] Beyene, A., Hailu, T., Faris, K., \& Kloos, H. (2015). Current state and trends of access to sanitation in Ethiopia and the need to revise indicators to monitor progress in the Post-2015 era. BMC public health, 15(1), 451.

[3] WHO (2010). Why urban health matters. World health day 2010. Available at: http://www.who.int/world-healthday/2010/media/whd2010background.pdf. Accessed on 20 June 2014 at 8:00 AM GMT.

[4] WHO and UNICEF (2014). Progress on Drinking Water and Sanitation: 2014 Update. World Health Organization, Geneva and United Nations Children's Fund, New York.

[5] UN-Habitat (2014). Situation Analysis of Informal Settlements in Addis Ababa. UN-Habitat. United Nations, Human Settlements Programme, Nairobi, Kenya.

[6] WHO \& UNICEF (2008). Progress on Drinking Water and Sanitation-Special Focus on Sanitation. WHO Press, Geneva, Switzerland.
[7] Cairncross, S. and Valdmanis, V. (2006). Water Supply, Sanitation, and Hygiene Promotion. In: Jamison, D.T. Breman, J. G., Measham, A.R., et al (Eds.). Disease control priorities in developing countries. $2^{\text {nd }}$ Edition. World Bank, World Bank and Oxford University Press, Washington, DC, pp 771-792.

[8] Hutton, G. (2013). Global costs and benefits of reaching universal coverage of sanitation and drinking-water supply. J Water Health, 11:1-12.

[9] MoUDC (2014), Urban Sanitation Strategy. The federal Democratic Republic of Ethiopia Ministry of Urban development and Construction (MoUDC), Addis Ababa, Ethiopia.

[10] UN-Habitat (2007). Situation Analysis of Informal Settlements in Addis Ababa. UN-Habitat. United Nations, Human Settlements Programme, Nairobi, Kenya.

[11] Kvarnström E, McConville J, Bracken P, Johansson M, Fogde M. The sanitation ladder-a need for a revamp? Journal of Water, Sanitation and Hygiene for Development. 2011;1:3-12.

[12] Bartram, J., \& Cairncross, S. (2010). Hygiene, sanitation, and water: forgotten foundations of health. PLoS Medicine, 7(11), e1000367.

[13] Daniel, W. W., \& Cross, C. L. (2008). Biostatistics: a foundation for analysis in the health sciences. 9th edition, Shon, Wily, \& Sons Inc. New Jersey, USA.

[14] Abraha, M. W., \& Nigatu, T. H. (2009). Modeling trends of health and health related indicators in Ethiopia (1995-2008): a time-series study. Health Res Policy Syst, 7(1), 29.

[15] Ethiopian-CSA (2014). Ethiopia Mini Demographic and Health Survey 2014. Ethiopian Central Statistical Agency (CSA), Addis Ababa, Ethiopia.

[16] Ethiopian-MWIE (2014). Unpublished data from Ethiopian Ministry of Water, Irrigation and Energy. Personal communication.

[17] Isunju, J. B., Schwartz, K., Schouten, M. A., Johnson, W. P., \& van Dijk, M. P. (2011). Socio-economic aspects of improved sanitation in slums: A review. Public health, 125(6), 368-376.

[18] Pullan RL, Freeman MC, Gething PW, Brooker SJ (2014) Geographical Inequalities in Use of Improved Drinking Water Supply and Sanitation across Sub-Saharan Africa: Mapping and Spatial Analysis of Cross-sectional Survey Data. PLoS Med 11(4): e1001626.

[19] Eshete, N., Beyene, A., \& Terefe, G. (2015). Implementation of Community-led Total Sanitation and Hygiene Approach on the Prevention of Diarrheal Disease in Kersa District, Jimma Zone Ethiopia. Science Journal of Public Health, 3(5), 669676. doi: 10.11648/j.sjph.20150305.22

[20] Gebru, T., Taha, M., Kassahun, W. (2013). Prevalence of Diarrheain Under-Five Children among Health Extension Model and Non-Model Households in Sheko District Rural Community, Southwest Ethiopia. Science Journal of Public Health, 1(5), 230-234. doi: 10.11648/j.sjph.20130105.18

[21] Konteh, F. H. (2009). Urban sanitation and health in the developing world: reminiscing the nineteenth century industrial nations. Health \& place, 15(1), 69-78. 
[22] Cairncross, S., Bartram, J., Cumming, O., \& Brocklehurst, C. (2010). Hygiene, sanitation, and water: what needs to be done?. PLoS medicine, 7(11), e1000365.

[23] Hopewell, Mike R., Graham Jay P. (2014). Trends in access to water supply and sanitation in 31 major Sub-Saharan African cities: an analysis of Demographic and Health Survey (DHS) data from 2000 to 2012. BMC Public Health 14, 208.

[24] Bhagwan, J. N., Still, D., Buckley, C., \& Foxon, K. (2008). Challenges with up-scaling dry sanitation technologies. Water Science and Technology, 58(1), 21.

[25] Katukiza, A. Y., Ronteltap, M., Oleja, A., Niwagaba, C. B., Kansiime, F., \& Lens, P. N. L. (2010). Selection of sustainable sanitation technologies for urban slums-A case of Bwaise III in Kampala, Uganda. Science of the total environment, 409(1), 52-62.

[26] Beyene, A., Addis, T., Kifle, D., Legesse, W., Kloos, H., \& Triest, L. (2009a). Comparative study of diatoms and macroinvertebrates as indicators of severe water pollution: Case study of the Kebena and Akaki rivers in Addis Ababa, Ethiopia. Ecological Indicators, 9(2), 381-392.

[27] Beyene, A., Legesse, W., Triest, L., \& Kloos, H. (2009b). Urban impact on ecological integrity of nearby rivers in developing countries: the Borkena River in highland Ethiopia. Environmental monitoring and assessment, 153(1-4), 461-476.

[28] Nyenje, P. M., Foppen, J. W., Uhlenbrook, S., Kulabako, R., \& Muwanga, A. (2010). Eutrophication and nutrient release in urban areas of Sub-Saharan Africa-a review. Science of the Total Environment, 408(3), 447-455.

[29] Beyene, A., Yemane, D., Addis, T., Assayie, A. A., \& Triest, L. (2014). Experimental evaluation of anaerobic digestion for coffee wastewater treatment and its biomethane recovery potential. International Journal of Environmental Science and Technology, 11(7), 1881-1886. 